\title{
BIOPROSPECÇÃO DE ISOLADOS DE Bacillus spp. COMO POTENCIAIS PROMOTORES DE CRESCIMENTO DE Eucalyptus urograndis ${ }^{1}$
}

\author{
Ana Ligia de Lima Moreira² e Fabio Fernando de Araújo²
}

\begin{abstract}
RESUMO - Objetivou-se neste trabalho avaliar características bioquímicas de interesse agronômico e correlação com a promoção de crescimento de plantas em isolados de Bacillus sp. originários da rizosfera de eucalipto. O trabalho foi conduzido em laboratório e casa de vegetação. A partir do isolamento de bactérias da rizosfera de plantas, oriundas de diferentes municípios da região oeste paulista, conseguiu-se 127 isolados de Bacillus spp. Foram realizados testes bioquímicos para caracterização dos isolados bacterianos quanto ao antagonismo a fungos fitopatogênicos, produção de auxinas, produção de amônia e atividade enzimática. Na etapa final foi avaliado o potencial dos isolados, caracterizados previamente em condições de laboratório, para promoção de crescimento de plantas, utilizando-se a inoculação das bactérias em mudas de eucalipto e cultivo das plantas em casa de vegetação durante 90 dias. Avaliou-se variáveis de crescimento do eucalipto objetivando-se selecionar os melhores isolados e também correlacionar as diferentes variáveis analisadas no trabalho. O protocolo de bioprospecção de Bacillus sp. na rizosfera foi válido para se encontrar rizobactérias promissoras no aumento do crescimento do eucalipto. Foram selecionados cinco isolados como promissores para ação no crescimento de eucalipto. O potencial antagônico a fungos fitopatogênicos e produção de amônia apresentados pelos isolados de rizobactérias foi útil na fase inicial de seleção de rizobactérias promotoras do crescimento de eucalipto, pois apresentou correlação significativa com o crescimento das plantas.
\end{abstract}

Palavras-chave: Rizobactérias; Reflorestamento; Microbiologiado solo.

\section{BIOPROSPECTIONOF Bacillus spp. AS POTENTIAL GROWTH PROMOTERS IN Eucalyptus urograndis}

\begin{abstract}
The objective of this study was to evaluate biochemical characteristics of agronomic interest and correlation with the promotion of plant grow thin isolates of Bacillus sp. originating from the eucalyptus rhizosp here. The experiment was conducted in laboratory and greenhouse. From the bacteria isolation from the rhizo sp here of plants from different cities of the western region of São Paulo, were obtained 127 isolates of Bacillus sp.. Biochemical testswere performed to characterize thebacterial isolateson the antagonism of pathogenic fungi, the production of auxin, ammonia and enzymatic activity. In the final ste pwe evaluated thepotentialof the isolates, previous lycharacterizedin laboratory conditions, to promote plant growth, using bacteria inoculation in eucalyptus seedling sand growing plants in a green house for 90 days. Eucalyptus growth were evaluated aiming to select the best strain sand to correlate the different variables asses sed. The bio prospecting protocol for Bacillus sp. Rhizosp here was valid to find promising rhizobacteria in increasing eucalyptus growth. Five isolates were selected as promising foracti on on growing eucalyptus. The antagonistic to pathogenic fungi and ammonia production found in isolate so frhizobacteria help fulin the initial selection of plant growth promoting rhizobacteria eucalyptus as significantly correlated with plant growth.
\end{abstract}

Keywords: Rhizobacteria; Refloresty; Soil Microbiology.

\footnotetext{
${ }^{1}$ Recebido em 13.09.2012 aceito para publicação em 27.08.2013.

${ }^{2}$ Universidade do Oeste Paulista, Faculdade de Ciências Agrárias, Agronomia. E-mail: <lygyamoreira@hotmail.com>e < fabio@unoeste.br>.
} 


\section{INTRODUÇÃO}

O Brasil atualmente ocupa a segunda posição no cenário mundial relacionado a área cultivada com espécies do gênero Eucalyptus, totalizando aproximadamente cinco milhões de hectares em 2011, sendo que $74 \%$ dessas florestas são destinadas para produção de papel e celulose (ABRAF, 2012).

As rizobactérias promotoras de crescimento de plantas (RPCP) são bactérias encontradas na rizosfera, podendo estar na superfície ou em associação com as raízes, sendo capazes de potencializar o crescimento da planta de maneira direta ou indireta (GALDIANO JUNIOR, 2011). As pesquisas sobre as RPCP tem aumentado cada vez mais desde que o termo foi utilizado pela primeira vez por Kloepper e colaboradores no final de 1970 (VESSEY, 2003). Entre os gêneros mais estudados destacam-se: Bacillus, Pseudomonas, Azospirillum e Rhizobium. Estes microrganismos tem ação sobre o desenvolvimento das plantas, incluindo os efeitos benéficos tanto na germinação de sementes, emergência de plântulas e crescimento das plantas (LAZZARETTI; BETTIOL, 1997). As RPCP agem de forma complexa, desta forma as rizobactérias podem apresentar uma combinação de ações positivas para o crescimento das plantas (AHMAD et al., 2008).

Estudos apontam sobre os benefícios advindos das RPCP no tocante a disponibilização de nutrientes para as plantas. Bactérias solubilizadoras de fosfato são comuns na rizosfera. Estas secretam ácidos orgânicos e/ou fosfatases que facilitam a conversão de formas insolúveis de fósforo para formas disponíveis para as plantas (KIM et al., 1998). Rizobactérias também assimilam as formas inorgânicas de $\mathrm{N}$ tornando-as constituintes orgânicos de suas células e tecidos. Os compostos sintetizados pelos microrganismos podem então ser parcialmente mineralizados tornando-se disponível para as plantas (ALFAIA, 2006).

As RPCP são capazes de estimular o crescimento das plantas atuando na redução dos níveis de etileno nas mesmas através da ação da enzima ACC desaminase (PRIGENT-COMBARET et al., 2008). Assim, a atividade da ACC desaminase diminuiria a produção de etileno nas raízes de plantas hospedeiras resultando em seu alongamento (GLICK et al., 1998). A promoção do crescimento radicular é um dos efeitos benéficos das RPCP, pois o estabelecimento rápido de raízes laterais e adventícias é uma característica vantajosa para plantas, aumentando a habilidade de se fixar ao solo e obter água e nutrientes do ambiente. Neste quesito existe a influência de moléculas fitoreguladoras como as auxinas que não funcionam como hormônio em células bacterianas, mas sua produção pelas bactérias pode ser devido a seu envolvimento na interação com as plantas (PATTEN; GLICK, 2002).

O crescimento de fungos, bactérias e nematoides fitopatogênicos, podem ser inibidos por vários microrganismos benéficos habitantes da rizosfera. A atividade e os efeitos antagonistas de microrganismos benéficos às plantas, atuando na rizosfera estão bem estudados para as bactérias pertencentes ao grupo das Proteobacteria (Pseudomonas e Burkholderia) e Firmicutes (Bacillus e gêneros afins) (RAAIJMAKERS et al., 2009). As rizobactérias podem suprimir as doenças envolvendo vários mecanismos de ação como: antagonismo relacionado à produção de antibióticos antifúngicos como a iturina em B. subtilis (ARAÚJO et al., 2005); competição por espaço e nutrientes com fitopatógenos e outros microrganismos prejudiciais à rizosfera (PEIXOTO,1997; ROBIN et al. 2008); e indução de resistência nas plantas (WALL; SANCHEZ, 1993).

A inoculação de rizobactérias em espécies florestais pode proporcionar ganhos consideráveis no desenvolvimento das plantas. Mafia et al. (2007) avaliando a indução biológica do enraizamento e crescimento de eucalipto por isolados de rizobactérias selecionou dois isolados de Bacillussubtilis, S1 e 3918, que foram mais efetivos para enraizamento e biomassa radicular, com incrementos de 40,6 e 114,2\%, respectivamente.

Objetivou-se neste trabalho avaliar características bioquímicas de interesse agronômico de isolados de Bacillusspp originários da rizosfera do eucalipto e correlação com a promoção de crescimento de plantas do próprio eucalipto.

\section{MATERIAL E MÉTODOS}

\subsection{Local de desenvolvimento dos trabalhos}

Os trabalhos de isolamento de Bacillus spp. e os bioensaios foram conduzidos no laboratório de microbiologia e fitopatologia da faculdade de Ciências Agrárias (FCA) -UNOESTE, Presidente Prudente, SP, durante os anos de 2011 e 2012. A parte experimental com avaliação do crescimento das plantas foi conduzida na casa de vegetação da UNOESTE, Presidente Prudente, SP. 


\section{2 Área de coleta das plantas}

As amostras de raízes foram coletadas de plantas jovens de Eucalyptus urograndis com aproximadamente um ano de idade, sendo acondicionadas em sacos plásticos e colocadas sob refrigeração até análise. As amostragens foram realizadas nos seguintes municípios localizados na região Oeste Paulista: Estrela do Norte (22²9’17"S 5140’40"W), Iepê (22³8’7"S 514’34"W), Itororó do Paranapanema - distrito de Pirapozinho (22³6’36"S 5143’15"W), Montalvão - Distrito de

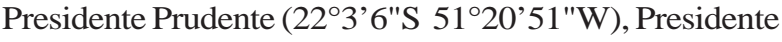

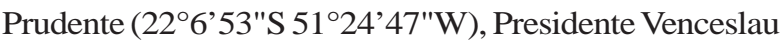

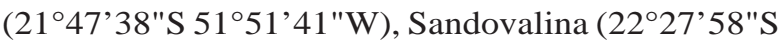

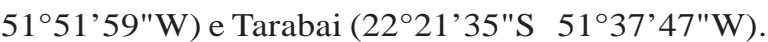

A caracterização da região investigada apresenta-se com precipitação pluvial de 1290 a 1350 mm, temperatura média anual de $24^{\circ} \mathrm{C}$, altitude acima de $400 \mathrm{~m}$ e a classificação do solo indica como LATOSSOLO VERMELHO os municípios de Estrela do Norte, Iepê, Itororó de Paranapanema, Sandovalina e Tarabai e ARGISSOLOS VERMELHO AMARELO para os municípios de P. Prudente e P. Venceslau (BRAIDO; TOMASELLI, 2012)

\subsection{Isolamento de Bacillus spp.}

No laboratório, a raiz de cada planta coletada foi lavada levemente para desprender o solo que estava mais frouxamente aderido e posteriormente a mesma foi fracionada em partes amostrando-se então $50 \mathrm{~g}$ que foram então introduzidas em frasco erlenmeyer com solução salina esterilizada (solução de $\mathrm{MgSO}_{4} \cdot 7 \mathrm{H}_{2} \mathrm{O}$ $0,01 \mathrm{M})$. O conjunto raiz solo que permaneceu aderido foi denominado ambiente rizosférico. Este conjunto, dentro do frasco foi submetido a 30 minutos de agitação em agitador orbital mecânico. Amostras de $1 \mathrm{~mL}$ retiradas do frasco foram submetidas a diluições seriadas em tubos com $10 \mathrm{~mL}$ de água destilada estéril. Antes do plaqueamento foram submetidas a um tratamento térmico $\left(80^{\circ} \mathrm{C} / 20 \mathrm{~min}\right)$ visando selecionar os microrganismos resistentes a este tratamento, onde se enquadra o gênero Bacillus (BUCHANAN; GIBBONS, 1975; BETTIOL, 1995). O plaqueamento foi realizado com alíquotas de $0,1 \mathrm{~mL}$, coletadas nos tubos após o choque térmico e distribuídas em meio AN (ágar nutritivo) com incubação por 48 horas, em estufa a $28^{\circ} \mathrm{C}$. As bactérias formadoras de colônias nas placas foram, então, isoladas e caracterizadas previamente como pertencente ao gênero
Bacillus, de acordo com a metodologia descrita por Li \& Alexander (1988).

No final da fase de amostragem e isolamento ficou constituído um grupo de 127 isolados bacterianos pertencentes ao gênero Bacillus originário da rizosfera de eucalipto, sendo a seguinte quantidade de isolados em cada local: Estrela do norte (EN) 10 isolados, Iepê (IE) 11 isolados, Itororó do Paranapanema (IT) 11 isolados, Montalvão (M) 10 isolados, Presidente Prudente (PP)15 isolados, Presidente Venceslau (PV) 39 isolados, Sandovalina (S) 21 isolados, Tarabai (T) 10 isolados. Os mesmos foram utilizados nas etapas posteriores. Os 127 isolados foram preservados em meio de cultura agar nutriente sob óleo mineral.

\subsection{Inibição de fungos fitopatogênicos in vitro}

Para avaliar os isolados quanto ao potencial de antagonismo a fungos fitopatogênicos foi utilizado o método de pareamento em placas de Petri contendo BDA [batata(250g.L L $\left.^{-1}\right)$ :dextrose(10g.L $\left.{ }^{-1}\right)$ :agar(15g.L - $\left.^{-1}\right)$ ] segundo metodologia descrita porporAraujo et al (2005). Foi utilizado o fungo fitopatogênico Aspergillusniger, que foi inoculado pela introdução de discos com micélio, em quatro pontos equidistantes na placa de petri com BDA, 24 horas antes da inoculação do Bacillus no centro da placa. Para cada isolado foram preparadas placas em duplicatas. As placas foram incubadas em estufa à $28^{\circ} \mathrm{C}$ por sete dias. Após este período, foram medidos os halos de inibição do crescimento, com auxílio de régua, medindo-se a distância da isolado até o micélio do fungo fitopatogênico.

\subsection{Avaliação da produção da enzima ACC desaminase}

Para estimativa da produção de amino ciclo propano carboxilato (ACC) desaminase utilizou-se o método descrito por Lucon et al. (2008), onde a capacidade de crescimento dos isolados, em presença de ACC, foi verificada em meio líquido pela incubação por $48 \mathrm{~h}$ a $27^{\circ} \mathrm{C}$, sob agitação constante. Foi utilizado um meio mínimo, com adição de 1-aminociclopropano-1-carboxilato (ACC) como única fonte de N (GLICK et al. 1995), com a seguinte composição: $4 \mathrm{~g}$ de $\mathrm{KH}_{2} \mathrm{PO}_{4}, 10 \mathrm{mg}$ de $\mathrm{H}_{3} \mathrm{BO}_{4}$, $6 \mathrm{~g}$ de $\mathrm{Na}_{2} \mathrm{HPO}_{4}, 10 \mathrm{mg}$ de $\mathrm{MnSO}_{4} .7 \mathrm{H}_{2} \mathrm{O}, 0,2 \mathrm{~g}$ de $\mathrm{MgSO}_{4} \cdot 7 \mathrm{H}_{2} \mathrm{O}, 70 \mathrm{mg}$ de $\mathrm{ZnSO}_{4}, 1 \mathrm{mg}$ de $\mathrm{FeSO}_{4} .7 \mathrm{H}_{2} \mathrm{O}$, $50 \mathrm{mg}$ de $\mathrm{CuSO}_{4}, 2 \mathrm{~g}$ de glicose, $10 \mathrm{mg}$ de $\mathrm{MoO}_{3}$, 2 g de ácido glucônico, 2 g de ácido cítrico, $3 \mathrm{mM}$ de ACC e $1 \mathrm{~L}$ de água destilada. Foram feitas duas repetições para cada isolado. A avaliação final foi realizada pela 
quantiifcação do crescimento bacteriano utilizando-se o método turbidimétrico (Romeiro, 2007) efetivado pela leitura de absorbância (595nm) em espectrofotômetro, comparando-se a leitura final (48 horas) com a do tempo zero.

\subsection{Ensaio de solubilização de fosfatos}

A avaliação dos isolados quanto à solubilização de fosfato foi realizada de acordo com o método descrito por Chagas Jr. (2010) utilizando-se meio líquido, contendo $10 \mathrm{~g}$ de glicose, $2 \mathrm{~g}$ de extrato de levedura, suplementado com 3 g de fosfato reativo (24\% de $\mathrm{P}_{2} \mathrm{O}_{5}$ insolúvel em agua). Após a inoculação dos isolados no meio de cultura o material ficou sob agitação constante no período de 7 dias. Logo após foi retirado $5 \mathrm{~mL}$ da solução e centrifugado por 10 min a 9000 RPM, Em seguida, o sobrenadante foi utilizado na determinação de fósforo solúvel que foi avaliado por espectrofotometria a 660nm, segundo procedimento descrito por Tedesco et al. (1995). Foram feitas duas repetições para cada isolado.

\subsection{Ensaio de produção de amônia pelos isolados}

Foi utilizado o método do reativo de Nessler para análise de produção de $\mathrm{NH}_{3}$. $\mathrm{O}$ mesmo foi preparado dissolvendo 100 g de iodeto de mercúrio (II) e 70 g de iodeto de potássio em $100 \mathrm{~mL}$ de água isenta de amônia, adicionando-se uma solução fria de 160 g de $\mathrm{NaOH}$ em 700 mL de água destilada e elevando a solução para um volume de 1L. As bactérias cresceram em meio liquido (caldo nutriente), após 24 horas de incubação foi adicionado $1 \mathrm{~mL}$ do reagente de Nessler e observada a presença de um precipitado amarelo-alaranjado, o qual indica haver a produção de amônia no meio. A cor é tanto mais intensa quanto maior a concentração das substâncias analisadas. O resultado foi obtido efetuando-se a leitura da absorbância (540 nm) em espectrofotômetro sendo o ensaio realizado em duplicata para cada isolado. (MARIANO; SILVEIRA, 2005).

\subsection{Ensaio para avaliação de produção do hormônio AIA (Acido Indol Acético)}

Para avaliação dos isolados de Bacillus sp. quanto ao potencial de produção de AIA foi conduzido bioensaio descrito originalmente por Tang e Bonner (1947) onde as bactérias foram cultivadas em $50 \mathrm{~mL}$ de meio líquido TSB (TrypticaseSoyBrooth) suplementado com $10 \mathrm{~g} \mathrm{~L}^{-1}$ de dextrose, $5 \mathrm{~g} \mathrm{~L}^{-1}$ de extrato de levedura e $5 \mathrm{mM}$ de $\mathrm{L}^{-1}$ triptófano (1000 ug $\mathrm{mL}^{-1}$ ). Os isolados foram mantidos a $28^{\circ} \mathrm{C}$, no escuro sob agitação constante, durante 24 horas. Após este período, foram centrifugados a 10000 x g durante 10 minutos, para a obtenção do sobrenadante. A quantidade de AIA por mL de cultura foi estimada através da mistura de $5 \mathrm{~mL}$ de reagente de Salkowski (EHMANN, 1977) com $1 \mathrm{~mL}$ do sobrenadante da cultura, seguido da leitura da absorbância em 500 nm, após 30 minutos. O ensaio foi realizado em duplicata para cada isolado. A concentração de AIA no meio de cultura foi determinada pela comparação com uma curva padrão determinada previamente com concentrações conhecidas do fitoregulador.

\subsection{Experimento para avaliação de promoção de crescimento de Eucalyptus urograndis.}

Todos os 127 isolados de Bacillus que foram caracterizados bioquimicamente foram utilizados no experimento final de casa de vegetação para avaliação da promoção do crescimento do eucalipto. O cultivo das plantas foi realizado em vasos plásticos com 5 kg de solo coletado em área agrícola, o qual tinha os seguintes atributos de fertilidade $\mathrm{pH}\left(\mathrm{CaCl}_{2}\right)=5,5 ; \mathrm{Al}$ $\left(\right.$ mmolc dm $\left.{ }^{-3}\right)=0 ;$ M.Orgânica $\left(\mathrm{g} \mathrm{dm}^{-3}\right)=12 ; \mathrm{P}\left(\mathrm{mg} \mathrm{dm}^{-3}\right)$ $=4,5 ; \mathrm{K}\left(\right.$ mmolc dm$\left.^{-3}\right)=2,3$; Ca $\left(\right.$ mmolc $\left.\mathrm{dm}^{-3}\right)=23,2$; e $\mathrm{V}(\%)=65,8$. Foi utilizado no experimento mudas clonais de EucalyptusUrograndis com 60 dias de idade com altura média de $20 \mathrm{~cm}$. As bactérias foram inoculadas na ocasião do plantio das mudas sendo adicionado, próximo das raízes, $0,1 \mathrm{~mL}$ de suspensão bacteriana contendo cada isolado na concentração de $10^{8}$ células por mL. A suspensão bacteriana foi obtida pela raspagem de células multiplicadas previamente em tubos com meio de cultura sólido (AN). A calibração da concentração de bactérias foi realizada com auxílio do método colorimétrico (ROMEIRO, 2007).

As plantas foram conduzidas durante 90 dias com reposição periódica de umidade ao solo visando atingir a capacidade de campo. Ao final do experimento as plantas foram coletadas e as raízes foram lavadas em água corrente, separando-se o sistema radicular da parte aérea das plantas. Posteriormente foi quantificada a massa seca das raízes e da parte aérea das plantas, após secagem em estufa a $60^{\circ} \mathrm{C}$ até obtenção de massa constante. Foi avaliada também a altura das plantas medida desde o início do caule até o ápice e o diâmetro do caule, medido a dois $\mathrm{cm}$ de altura do solo. O experimento foi implantado em blocos no delineamento inteiramente causalizados consistindo de 127 tratamentos 
(isolados bacterianos) com quatro repetições por tratamento. Cada parcela foi representada por uma planta.

\subsection{Análises estatística}

No estudo das variáveis bioquímicas analisadas nos isolados bacterianos foram utilizados histogramas com distribuição da frequência em seis intervalos prédefinidos, visando avaliar o agrupamento dos isolados nas diferentes classes

Os dados obtidos no experimento de casa de vegetação foram analisados estatisticamente pelo programa Sisvar com determinação do valor de F e quando significativo utilizou-se o teste Scott Knott para comparação de médias. Foi utilizado também o programa Sigmaplot para efetuar a correlação de Pearson entre as variáveis bioquímicas e de crescimento das plantas.

\section{RESULTADOS}

A caracterização dos 127 isolados bacterianos quanto ao antagonismo fúngico mostrou que, aproximadamente, $15 \%$ dos isolados apresentaram maior ação para inibir o crescimento do fungo Aspergillusniger utilizado com referência neste critério (Figura 1A). A maioria dos isolados ficou agrupada na menor classe de inibição (0-0,6 cm). A avaliação da atividade da enzima ACC desaminase revelou que aproximadamente $80 \%$ dos isolados foram agrupados na classe de menor crescimento bacteriano avaliado pela turbidimetria (Figura 1B).

Quanto ao potencial para solubilização de fosfatos encontrado nos isolados verificou-se que a maioria apresentou baixos valores detectados pela leitura espectrofotométrica (figura 1C). Poucos isolados foram classificados nas classes de maior potencial nesta característica. Observou-se também que apesar da maioria dos isolados aparecerem como positivos quanto à produção de amônia poucos foram freqüentes nas classes de maiores valores (Figura 1D).

Todos os isolados bacterianos avaliados foram considerados positivos no ensaio de produção de auxinas (Figura 1E). Aproximadamente 85\% dos isolados foram classificados em dois grupos de frequência que representam os valores mais baixos de concentração do hormônio, considerando-se a distribuição de frequência utilizada.
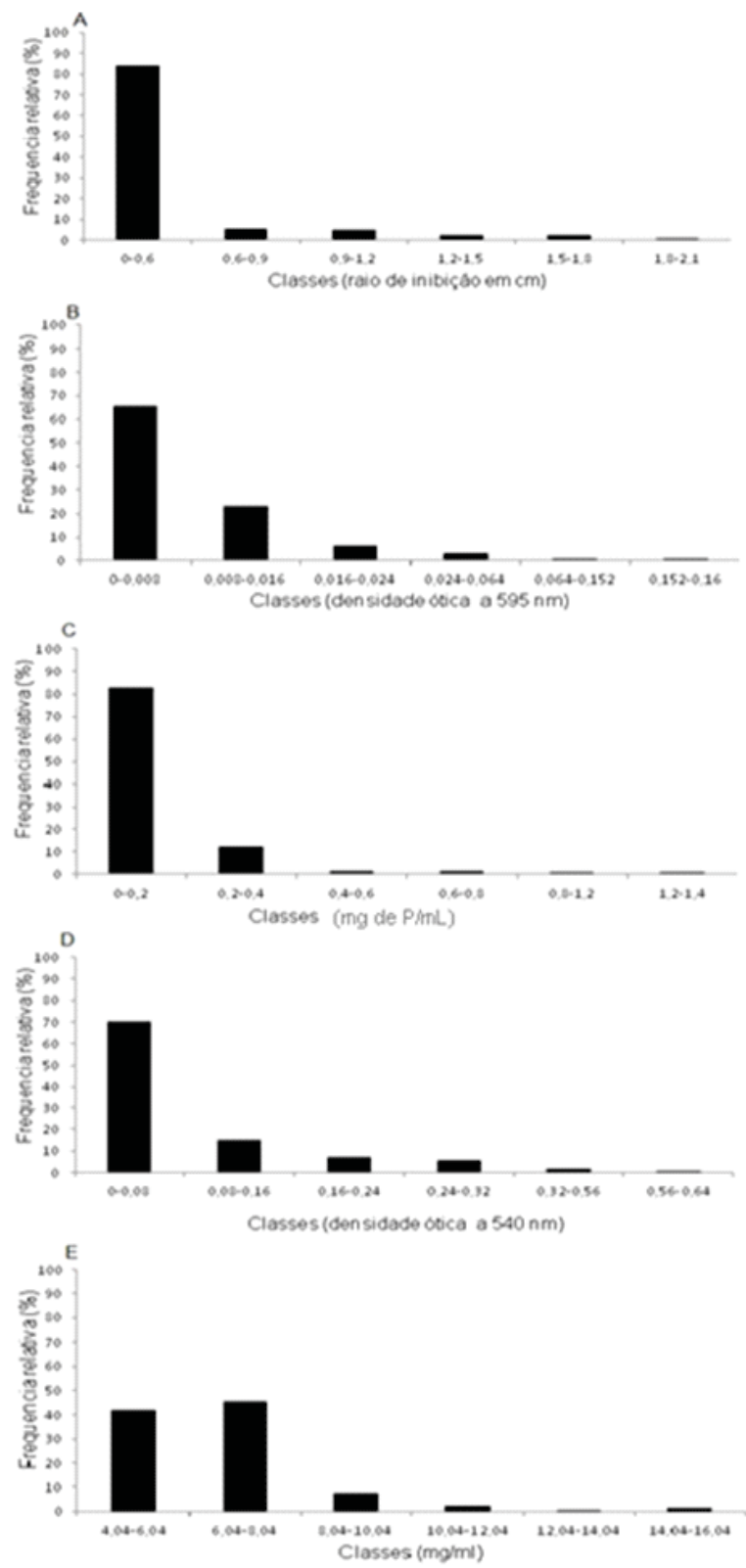

Figura 1 - Histogramas de frequência dos 127 isolados bacterianos em seis classes.(A) - Antagonismo a Aspergillusniger; (B) capacidade de crescimento em meio com adição de 1-aminociclopropano-1-carboxilato (ACC); (C) Solubilização de fosfatos; (D) Produção de amônia;e (E) Produção de auxinas.

Figure 1 - Frequencyhistograms of 127 isolates into six classes (A) - Antagonism Aspergillusniger, (B) the ability to grow in a medium with addition of 1 aminocyclopropane-1-carboxylate (ACC), ( C) Phosphate solubilization (d) Production of ammonia, (E) Production of auxins.

Revista Árvore, Viçosa-MG, v.37, n.5, p.933-943, 2013 
No resumo da avaliação de crescimento das plantas (Tabela 1), encontrou-se que apenas a variável massa seca da parte aérea proporcionou valores de F significativo $(\mathrm{p}<0,05)$.

Dos 127 isolados avaliados dentro da variável produção de massa seca das plantas, 15 apresentaram potencial para promoção do crescimento do eucalipto (Tabela 2). Pode ser observado também que dentro deste grupo cinco isolados (s32, s24, s31,s13, e s25) apresentaram desempenho significativamente maiores que os outros na promoção de crescimento do eucalipto. Esses isolados também são originários da rizosfera de plantas coletadas na mesma localidade (Sandovalina).

Com relação à interação entre características bioquímicas encontrados nos isolados bacterianos e efeito sobre o crescimento das plantas encontrou-se que a ação de antagonismo a fungo e a produção de amônia foram as variáveis bioquímicas que apresentaram correlações significativas com a maioria das variáveis de crescimento das plantas (Tabela 3). Pode também se destacado a correlação positiva, significativa a $1 \%$ de probabilidade, da característica de antagonismo das rizobacterias ao fungo fitopatogênico com a massa seca da raiz de eucalipto.

\section{DISCUSSÃO}

Observou-se baixa frequência dos isolados bacterianos na produção de maiores concentrações de ACC desaminase (Figura 1). Marques et al. (2010) em avaliação de isolados bacterianos para promoção de crescimento em milho encontraram atividade significativa da ACC desaminase em 50\% dos isolados. A produção da enzima ACC desaminase por rizobactérias ajuda a manter o crescimento e desenvolvimento de plantas sob condições de estresse, mesmo durante as infecções causadas por fitopatógenos (SALEEM et al., 2007).
A solubilização de P na rizosfera é um modo comum de ação sugerido em RPCP, pois aumenta a disponibilidade de nutrientes para as plantas hospedeiras, e apesar das rizobactériassolubilizadoras de fosfato apresentar potencial de uso como inoculantes, sua aplicação permanece limitada devido à falta de conhecimento sobre ecologia microbiana e dinâmica das populações no solo em ambientes não controlados (RICHARDSON, 2000).

Neste estudo verificou-se que os isolados de rizobactérias expressaram pouca atividade no quesito de solubilização de fosfatos, indicando que esta avaliação realizada em condição controlada pode não representar a ação dessas rizobactérias nos solos com deficiência de fosfatos solúveis.

Marques et al. (2010) detectaram a produção de amônia na maioria dos isolados bacterianos avaliados para promoção do crescimento em milho, de forma semelhante também foi encontrada esta produção na maioria dos isolados avaliados neste estudo. Esses autores também afirmaram que a capacidade das espécies bacterianas na produção de amônia também colabora para o crescimento das plantas. Deve ser enfatizado que o método de detecção da presença de amônia utilizado no estudo apenas fornece uma indicação da produção dessa molécula, sendo necessários outros estudos para maior precisão na quantificação da mesma.

Neste estudo todos os isolados produziram auxina, porém a grande maioria em pequena quantidade, entretanto de acordo com Glick et al. 1998 cerca de 80\% de isolados de rizobactérias provenientes do solo são hábeis para produzir auxinas. Teixeira et al. (2005) relataram que em seleção de isolados promissores para estimulação de enraizamento em eucalipto apenas 20\% produziram auxinas in vitro e ainda em baixas concentrações. Teixeira et al. (2007) encontraram dois isolados capazes de produzir ácido indol-acético (AIA)

Tabela 1 - Resumo da análise de variância com valores obtidos pelo teste F nas seguintes variáveis: altura, diâmetro do caule, massa seca da parte aérea e massa seca das raízes de eucalipto inoculado com rizobactérias.

Table 1 - Summary of the analysis of variance with values obtained by the F test in the following variables: height, stem diameter, dry weight of shoots and roots, and dry mass of eucalyptus inoculated with rhizobacteria.

\begin{tabular}{ccccc}
\hline Fonte de variação & Altura $(\mathrm{cm})$ & Diâmetro $(\mathrm{cm})$ & $\begin{array}{c}\text { Massa seca da parte aérea } \\
\text { (g por planta) }\end{array}$ & $\begin{array}{c}\text { Massa seca da raiz } \\
\text { (g por planta) }\end{array}$ \\
\hline Tratamento & 1,08 & 1,16 & $2,75^{*}$ & 1,29 \\
C.V. $(\%)$ & 11,21 & 15,82 & 31,56 & 24,20 \\
\hline
\end{tabular}

*Significativo a $5 \%$ de probabilidade **significativo a $1 \%$ de probabilidade

Revista Árvore, Viçosa-MG, v.37, n.5, p.933-943, 2013 
Bioprospecção de isolados de Bacillus spp. Como potenciais...

Tabela 2 - Avaliação de massa seca (MS) da parte aérea de eucalipto aos 90 dias de idade após a inoculação com 127 isolados de rizobactérias.

Table 2 - Evaluation of dry matter (DM) of shoots of eucalyptus at 90 days of age after inoculation with 127 isolates of rhizobacteria.

\begin{tabular}{|c|c|c|c|c|c|c|c|}
\hline Isolados & MS(g.pl $\left.{ }^{-1}\right)$ & Isolados & MS(g.pl $\left.{ }^{-1}\right)$ & Isolados & MS(g.pl $\left.{ }^{-1}\right)$ & Isolados & $\operatorname{MS}\left(\mathrm{g} \cdot \mathrm{pl}^{-1}\right)$ \\
\hline v128 & $4,95 c$ & v211 & $7,36 \mathrm{c}$ & v214 & $8,37 c$ & s14 & $9,19 c$ \\
\hline v325 & $5,26 c$ & s46 & $7,37 c$ & pp33 & $8,39 c$ & $\mathrm{t} 22$ & $9,23 c$ \\
\hline v413 & $5,39 c$ & $\mathrm{t} 12$ & $7,38 c$ & pp31 & $8,41 c$ & it23 & $9,25 c$ \\
\hline ie23 & $5,48 c$ & v115 & $7,45 c$ & $\mathrm{~m} 23$ & $8,42 c$ & s41 & $9,31 \mathrm{c}$ \\
\hline v322 & $5,62 \mathrm{c}$ & s11 & $7,46 \mathrm{c}$ & ie25 & $8,45 c$ & m32 & $9,33 c$ \\
\hline ie24 & $5,94 c$ & ie14 & $7,49 c$ & v114 & $8,46 c$ & pp15 & $9,36 c$ \\
\hline v315 & $6,13 c$ & pp25 & $7,62 c$ & v113 & $8,57 c$ & en13 & $9,37 c$ \\
\hline v122 & $6,15 c$ & v111 & $7,64 c$ & v314 & $8,60 \mathrm{c}$ & pp12 & $9,43 c$ \\
\hline en 11 & $6,31 c$ & s25 & $7,64 c$ & en21 & $8,61 c$ & v422 & $9,54 c$ \\
\hline v412 & $6,32 c$ & v312 & $7,64 c$ & ie21 & $8,65 c$ & $\mathrm{t} 11$ & $9,57 c$ \\
\hline v213 & $6,37 c$ & v112 & $7,75 c$ & it31 & $8,68 c$ & $\mathrm{~m} 21$ & $9,70 \mathrm{c}$ \\
\hline v411 & $6,40 c$ & $\mathrm{~m} 11$ & $7,79 c$ & en 12 & $8,72 c$ & it21 & $9,74 \mathrm{c}$ \\
\hline v323 & $6,45 c$ & m33 & $7,80 \mathrm{c}$ & s44 & $8,73 c$ & en 15 & $9,77 \mathrm{c}$ \\
\hline v321 & $6,54 c$ & v424 & $7,83 \mathrm{c}$ & it22 & $8,77 c$ & it26 & $9,85 \mathrm{c}$ \\
\hline en24 & $6,54 c$ & m34 & $7,85 \mathrm{c}$ & $\mathrm{m} 13$ & $8,77 c$ & v421 & $9,94 \mathrm{c}$ \\
\hline v423 & $6,57 c$ & pp11 & $7,85 \mathrm{c}$ & ie11 & $8,77 c$ & ie15 & $9,94 \mathrm{c}$ \\
\hline en25 & $6,60 c$ & $\mathrm{~m} 12$ & $7,86 \mathrm{c}$ & s12 & $8,81 c$ & s42 & $10,40 \mathrm{c}$ \\
\hline v215 & $6,65 c$ & v127 & $7,87 c$ & v313 & $8,82 c$ & s33 & $11,00 \mathrm{~b}$ \\
\hline v415 & $6,68 c$ & pp22 & $7,87 c$ & v116 & $8,83 c$ & v311 & $11,25 b$ \\
\hline ie22 & $6,73 c$ & $\mathrm{t} 31$ & $7,89 c$ & m31 & $8,86 \mathrm{c}$ & pp24 & $11,60 \mathrm{~b}$ \\
\hline v125 & $6,90 \mathrm{c}$ & $\mathrm{t} 32$ & 7,92c & it 12 & $8,87 c$ & s22 & $11,73 b$ \\
\hline $\mathrm{t} 14$ & $6,91 c$ & pp14 & $7,95 c$ & $\mathrm{~m} 22$ & $8,87 c$ & pp34 & $11,93 b$ \\
\hline $\mathrm{t} 13$ & $6,92 c$ & pp13 & $7,95 \mathrm{c}$ & $\mathrm{t} 21$ & $8,89 c$ & pp35 & $12,39 b$ \\
\hline en22 & $7,05 \mathrm{c}$ & en23 & $7,95 c$ & pp23 & $8,91 c$ & pp21 & $12,68 b$ \\
\hline it27 & $7,06 \mathrm{c}$ & t33 & $7,95 \mathrm{c}$ & pp32 & $8,91 \mathrm{c}$ & s23 & $13,41 b$ \\
\hline v324 & $7,08 \mathrm{c}$ & ie12 & $8,06 c$ & v414 & $9,03 c$ & s15 & $13,75 b$ \\
\hline s45 & $7,16 \mathrm{c}$ & s34 & $8,09 c$ & v425 & $9,06 \mathrm{c}$ & s21 & $14,11 b$ \\
\hline ie13 & $7,21 \mathrm{c}$ & it11 & $8,12 c$ & v426 & $9,07 c$ & s32 & $14,64 a$ \\
\hline ie26 & $7,21 \mathrm{c}$ & v123 & $8,16 c$ & it25 & $9,10 \mathrm{c}$ & s24 & $15,68 \mathrm{a}$ \\
\hline Testemunha & $7,25 c$ & it24 & $8,24 c$ & v126 & $9,11 \mathrm{c}$ & s31 & $15,72 \mathrm{a}$ \\
\hline s43 & $7,27 \mathrm{C}$ & v212 & $8,26 c$ & t23 & $9,13 \mathrm{c}$ & s13 & $16,30 \mathrm{a}$ \\
\hline v124 & $7,36 \mathrm{c}$ & it32 & $8,35 c$ & en 14 & $9,17 \mathrm{c}$ & s25 & $19,17 \mathrm{a}$ \\
\hline
\end{tabular}

Letras iguais na colunas não diferem estatisticamente pelo teste de Scott-knott a 5\% de significância.

Tabela 3 - Correlação de Pearson entre variáveis de crescimento e características bioquímicas nas rizobactérias promotoras de crescimento de eucalipto selecionadas neste estudo.

Table 3 - Pearson correlation between growth variables and biochemical characteristics of the selected growth promoting rhizobacteria in Eucalyptus.

\begin{tabular}{lccccc}
\hline Fontes de variação & ACC desaminase & Fosfatase & Antagonismo & Produção de amônia & AIA \\
\hline Massa seca parte aérea & $-0,228$ & $-0,253$ & $0,305^{*}$ & 0,035 & $-0,061$ \\
Massa seca raiz & $-0,181$ & 0,076 & $0,689^{* *}$ & 0,075 & $-0,083$ \\
Diâmetro do caule & 0,081 & 0,190 & $-0,122$ & $0,353^{*}$ & $-0,071$ \\
Altura da planta & $-0,360 *$ & 0,205 & $0,426^{*}$ & $0,382^{*}$ & 0,281 \\
\hline
\end{tabular}

* e**Significativo a $5 \%$ e $1 \%$ de probabilidade, respectivamente 
in vitro, e quando comparados ao tratamento de miniestacas de eucalipto em ácido indolbutírico (AIB), estes isolados promoveram incrementos significativos na porcentagem de enraizamento e na massa seca do sistema radicular de miniestacas.

A maioria dos trabalhos com a utilização de isolados do gênero Bacillus na agricultura tem sido relacionado ao controle biológico de fungos fitopatogênicos (BETTIOL, 1991) o qual tem sido atribuído com freqüência a produção de antibióticos (ARAUJO et al., 2005). A produção de antibióticos em rizobactérias tem sido correlacionada com a eficiencia de biocontrole em alguns estudos (FENTON et al., 1992).

Foi apresentado, neste estudo, que o antagonismo a fungos foi uma característica que se correlacionou com o crescimento do eucalipto. Contudo, Mafia et al. (2009) relataram que nem sempre a produção de antibióticos pode correlacionar com a eficiência de biocontrole. Sobre isto, em estudo de biocontrole de fungos causadores de podridão em eucalipto foi encontrado que o isolado de melhor desempenho no aumento do crescimento das plantas não se caracterizou como de maior antagonismo à fungos in vitro. Por outro lado, Cunha (2006), comprovou que isolados de rizobactérias inibiram o crescimento in vitro de bactérias fitopatogênicas ao Eucalyptus spp., também promoverem aumento no crescimento do sistema radicular e parte aérea dessa espécie. De acordo com Araujo et al. (2011), em trabalho de bioprospecção de rizobactérias promotoras de crescimento em alface foi constatado que o antagonismo da rizobactérias a um fungo fitopatogênico é importante critério de avaliação para ser utilizado nos programas de seleção de rizobactérias promotoras de crescimento de plantas.

Outro aspecto importante a mencionar é a possibilidade da inoculação de Bacillus subtlis no substrato de mudas induzir resistência a doenças como a ferrugem do eucalipto (PEREIRA et al., 2008).

A avaliação do enraizamento das plantas tem sido priorizado em alguns estudos de inoculação de rizobactérias no eucalipto, entretanto estes experimentos tem sido realizados em períodos menores de 20 a 25 dias após a inoculação das rizobactérias (MAFIA et al., 2007; TEIXEIRA et al., 2007). Desta forma, neste estudo, pode ter ocorrido estímulo ao enraizamento das plantas no início do experimento, mas esta ação pode não ter sido destacada aos 90 dias após a inoculação.
Verificou-se que os isolados bacterianos mais promissores proporcionaram aumentos da ordem de 53 a $167 \%$ na produção de massa seca na parte aérea de Eucalyptus urograndis, quando comparado ao controle (Tabela 2). Em estudo semelhante Diaz et al. (2009) encontraram 32 estirpes de Bacillus spp em 132 estirpes avaliadas, com ação de aumento da ordem de 69 a 191\% no enraizamento de Eucalyptusglobulus clonado. Aumentos da biomassa da ordem de $44 \%$ foram encontrados como resultado da inoculação de Bacillusmegaterium em experimento com mudas de Eucalyptus sp. em vasos (LUCY et al., 2004). Em estudo de isolamento e seleção de rizobactérias em Pinus taeda concluiu-se que entre as 99 rizobactérias testadas apenas seis foram selecionadas por promoverem ganhos que variaram de 10 a $16 \%$ no crescimento das plantas (BRUNETTA et al., 2010).

A ocorrência de espécies do gênero Bacillus no solo sob Eucalyptus sp. poderia indicar uma afinidade com a rizosfera desse tipo de árvore, já que ele foi encontrado em menor concentração no solo sob mata (PEREIRA et al., 2008). O fato da maioria dos isolados promissores estar relacionado a uma determinada localidade amostrada (Tabela 2) pode estar relacionada a fatores edáficos, como tipo de solo (BASHAN, 1995) e também outros fatores como tempo de cultivo (MOCALI et al., 2003) e uso do solo (ALVEY et al., 2003). Segundo Teixeira (2007) alguns isolados bacterianos avaliados como promotores de crescimento de plantas apresentaram especificidade ao clone de eucalipto empregado, indicandose com isto que os isolados que promovem o crescimento de uma espécie de planta podem ser ineficazes em outras.

Os isolados de rizobactérias que foram selecionadas como promotores de crescimento do eucalipto devem ser melhor estudados quanto às suas características genéticas. Sendo necessários novos estudos a partir da identificação desses isolados bacterianos para uso como inoculantes para cultura do eucalipto. O protocolo de bioprospecção de isolados de Bacillus sp. no solo foi válido para se encontrar rizobactérias promissoras no aumento do crescimento do eucalipto.

\section{CONCLUSÃO}

Foram selecionados cinco isolados de Bacillus sp. (s32, s24, s31,s13, e s25) como promissores para ação no crescimento de Eucalyptusurograndis. O antagonismo a fungos fitopatogênicos e a produção 
de amônia foram identificados como características bioquímicas importantes para validação de isolados de Bacillus sp. na fase inicial de seleção de rizobactérias promotoras do crescimento de eucalipto.

\section{REFERENCIAS}

AHMAD, F.; AHMAD, I.; KHAN, M. S. Screening of free-living rhizospheric bacteria for their multiple plant growth promoting activities. Microbiological Research, v.163, n.2, p.173-181, 2008.

ALFAIA, S. S. Caracterização e distribuição das formas do nitrogênio orgânico em três solos da Amazônia Central. Acta Amazonica,v.36, n.2, p.135-140, 2006.

ALVEY, S. et al.Cereal/legume rotation effects on rhizosphere bacterial community structure in West African soils. Biology and Fertility of Soils, v.37, n.1, p.73-82,2003

ARAUJO, F. F.; HUNGRIA, M.; HENNING, A.A.Phytohormones and antibiotics produced by Bacillussubtilis and their effects on seed pathogenic fungi and on soybean root development. World Journal of Microbiology and Biotechnology, v.21, n.8/9, p.1639-1645, 2005.

ARAUJO, F. F.et al.Produção de auxinas, fosfatases e antagonismo a fitopatógeno por rizobactérias e correlação com o crescimento da alface. In: CONGRESSO BRASILEIRO DE CIÊNCIAS DO SOLO, 33., 2011, Uberlândia. Anais... Uberlândia: Center Convention, 2011. CD ROM.

\section{ASSOCIAÇÃO BRASILEIRA DE FLORESTAS} PLANTADAS - ABRAF-. Anuário

Estatístico 2012. Disponível em: http:// www.abraflor.org.br/estatisticas/ABRAF12/ ABRAF12-BR.pdf Acesso em: 30 de mar. de 2012.

BASHAN, Y. et al. Survival of Azospirillumbrasilense in Bulk and Rhizosphere of 23 soil types. Applied Environmental Microbiology, v.5, p.1938-1945, 1995.

BETTIOL, W. Isolamento seletivo de Bacillus. In: MELO, I.S.; SANHUEZA, R.M.V. (Coord.) Métodos de seleção de microrganismos antagônicos a fitopatógenos. Jaguariúna: Embrapa-CNPMA, 1995.p.35-36.
BetTiOL, W. Controle biológico de doenças de plantas. Jaguariúna: EmbrapaCNPMA, $1991.452 \mathrm{p}$.

BRAIDO, L. M. H.; TOMASELLI, J.T.G. Setorização de fatores ambientais - clima, solos e relevo para o planejamento ambiental e territorial na região do pontal do Paranapanema SP - Brasil. Revista Geonorte, v.3, n.4, p.1268-1282, 2012.

BRUNETTA, J. M. F. C. et al.Isolamento e seleção de rizobactérias promotoras do crescimento de Pinus taeda. RevistaÁrvore, v.34, n.3, p.399406, 2010.

BUCHANAN, R. E.; GIBBONS, N. G. Bergey's manual of determinative bacteriology. 8.ed. Baltimore: The Willians \& Wilkens, 1975.

CHAGAS JR., A. F. et al.Capacidade de solubilização de fosfatos e eficiência simbiótica de rizóbios isolados de solos da Amazônia.

Acta Scientiarum Agronomy, v.32, n.3 p.359-366, 2010.

CUNHA, J. F.et al. Efeito "in vitro" de antibióticos e rizobactérias no controle de bactérias fitopatogênicas ao Eucalyptus spp. Revista Árvore, v.30,n.1, p.76-81, 2006.

DIAZ, K. et al. Root-promoting rhizobacteria in Eucalyptus globulus cuttings World Journal of Microbiology and Biotechnology, v.25, n.4, p.867-873, 2009.

LAZZARETI, E.; BETTIOL, W. Tratamento de sementes de arroz, trigo, feijão e soja com um produto formulado a base de células e de metabólitos de Bacillus subtilis. Scientia Agricola, Piracicaba, v. 54, n.1 p. 89-96, 1997.

LI, D.; ALEXANDER, M. Co-inoculation with antibioticproducing bacteria to increase colonization and nodulation by rhizobia. Plant Soil, v.108, n.1, p.211-219, 1988.

LUCON, C. M. M.; AKAMATSU, M. A.; HARAKAVA, R. Promoção de crescimento e controle de tombamento de plântulas de pepino por rizobactérias. Pesquisa Agropecuária Brasileira, v.43, n.6, p.691-697, 2008.

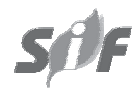

Revista Árvore, Viçosa-MG, v.37, n.5, p.933-943, 2013 
LUCY, M.; REED, E.; GLICK, B.R. Applications of free living plant growth-promoting rhizobacteria. Antonie Leeuwenhoek, v.86, n.1, p.1-25, 2004.

GALDIANO JR., R. F. Isolamento, identificação e inoculação de bactérias produtoras de auxinas associadas às raízes de orquídeas. Jaboticabal. Disponível em: <http://www.fcav.unesp.br/download/pgtrabs/ gmp/m/3614.pdf>Acesso em: 10 de set. de 2011.

GLICK, B. R. The enhancement of plant growth by free-living bacteria. Canadian Journal of Microbiology, v.41, n.1, p.109-117, 1995.

GLICK, B.R.; PENROSE, D.M.; LI, J. A model for the lowering of plant ethylene concentrations by plant growth-promoting bacteria. Journal of Theoretical Biology, v.190, n.1, p.63-68, 1998.

EHMANN, A. The van urk - salkowski reagenta sensitive and specific chromogenic reagent for silica gel thin-layer chromatographic detection and identification of indolederivates. Journal of Chromatography, v.132, n.2 p.267-276, 1977.

FENTON, A. M. et al. Exploitation of gene(s) involved in 2,4- diacetylphloroglucinol biosynthesis to confer a new biocontrol capacity to Pseudomonas strains. Applied and Environmental Microbiology, v.58, n.11, p.3873-3878, 1992.

KIM, K. Y.; JORDAN, D.; MCDONALD, G. A. Effect of phosphate solubilizing bacteria and vesicular-arbuscularmycorrhizae on tomato growth and soil microbial activity.

Biology and Fertility of Soils, v.26, n.1, p.79-87, 1998 .

PATTEN, C.L.; GLICK, B.R. Role of Pseudomonas putidaindol-acetic acid in development of the host plant root system. Applied and Environmental Microbiology, v.68, n.11, p.3795-3801, 2002.

MAFIA, R.G.et al.Efeito de rizobactérias sobre o enraizamento e crescimento de clones de eucalipto em diferentes condições de propagação clonal. Revista Árvore, v.31, n.5, p.813-821, 2007.
MARIANO, R.; SILVEIRA, E.B. Manual de práticas em fitobacteriologia.2.ed. Recife: Universidade Federal Rural da Paraíba, 2005.

MARQUES, A. P. G. C.et al.Assessment of the plant growth promotion abilities of six bacterial isolates using Zea mays as indicator plant. Soil Biology and Biochemistry, v.42, n.5, p.1229-1235, 2010.

MOCALI, S.et al. Fluctuation of bacteria isolated from elm tissues during different seasons and from differentplant organs. Research Microbiology, v.154, n.1, p.105-114, 2003.

PEIXOTO, A. R. Controle biológico da murcha bacteriana do tomateiro, por Pseudomonas spp. fluorescentes. Ciência Rural , v.27, n.1, p.153160, 1997.

PEREIRA, R. M.et al.Avaliação de populações de possíveis rizobactérias em solos sob espécies florestais. Revista Brasileira de Ciência do Solo, v.32, n.5, p.1921-1927, 2008.

PRIGENT-COMBARET, C.et al. Physical organization and phylogenetic analysis of acdR as leucineresponsive regulator of the 1 -

aminocyclopropane-1-carboxylate deaminase gene acdS in phytobeneficial Azospirillumlipoferum 4B and other Proteobacteria. FEMS

Microbiology Ecology, v.65, n.1, p.202-219, 2008.

RAAIJMAKERS. J. M. et al. The rhizosphere: a playground and battlefield for soilborne pathogens and beneficial microorganisms. Plant and Soil, v.321, n.2, p.341-361 2009.

RICHARDSON, A. E. Prospects for using soil microrganisms to improve the acquisition of phosphorus by plants. Australian Journal of Plant Physiology, v.28, n.9, p.897-906, 2000.

ROBIN, A. et al. Iron dynamics in the rhizosphere: consequences for plant health and nutrition. Advances in Agronomy, v.99, n.1, p.183-225, 2008. 
ROMEIRO, R.S. Controle biológico de doenças de plantas: procedimentos. Viçosa, MG: UniversidadeFederal de Viçosa, 2007.172p.

SALEEM, M. et al. Perspective of plant growth promoting rhizobacteria (PGPR) containing ACC deaminase in stress agriculture. Jounal of Industrial Microbiology and

Biotechnology, v.34, n.3, p.635-648, 2007.

WALL, G.C.; SANCHEZ, J.L. A biocontrol agent for Pseudomonas solanacearum. In: HATMAN, G.L.; HAYWARD, A.C. (Ed.). Bacterial wilt.ACIAR Proceeding, 1993.p.320-321.

TANG, Y. W.; BONNER, J. The enzymatic inactivation of indole-acetic, acid. Archives of Biochemistry and Biophysics, v.13, n,1, p.11-25, 1947.
TEIXEIRA, D. A. et al. Evidências de indução de resistência sistêmica à ferrugem do Eucalyptus sp. mediada por rizobactérias promotoras do crescimento de plantas.Fitopatologia Brasileira, v.30, p.350-356, 2005.

TEDESCO, M. J.et al. Análise do solo, plantas e outros materiais. Porto Alegre: Universidade Federal do Rio Grande do Sul, 1995. 174p.

TEIXEIRA, D. A.et al. Rhizobacterial promotion of eucalypt rooting and growth. Brazilian Journal of Microbiology, v.38, n.1, p.118123, 2007.

VESSEY, J. K. Plant growth promoting rhizobacteria as biofertilizers. Plant and Soil, v.255, n.2, p.571-586, 2003. 
